\title{
Training requirements for the agro-food industry in Portugal
}

\author{
Pedro D. Gaspar ${ }^{a}$, Rita Pinheiro ${ }^{\mathrm{b}}$, Cláudia Domingues ${ }^{\mathrm{c}}$, Celestino Almeida $^{\mathrm{d}}$, \\ Teresa Paiva ${ }^{\mathrm{e}}$, Carlos D. Pereira ${ }^{\mathrm{f}}$, and Manuela Vaz Velho ${ }^{\mathrm{b}^{*}}$ \\ ${ }^{a}$ Universidade da Beira Interior, Rua Marquês de Ávila e Bolama, 6201-001 Covilhã \\ b Escola Superior de Tecnologia e Gestão, Instituto Politécnico de Viana do Castelo, Avenida Atlântico, \\ 4900-348 Viana do Castelo \\ c InovCluster - Associação do Cluster Agro-Industrial do Centro, Centro de Apoio Tecnológico Agro-Alimentar, \\ Zona Industrial de Castelo Branco Rua A, 6000-459 Castelo Branco \\ d Escola Superior Agrária, Instituto Politécnico de Castelo Branco, Quinta da Senhora de Mércules, Apt. 119, \\ 6001-909 Castelo Branco \\ e Escola Superior de Tecnologia e Gestão, Instituto Politécnico da Guarda Av. Dr. Francisco Sá Carneiro, 50, \\ 6300-559 Guarda \\ ${ }^{\mathrm{f}}$ Escola Superior Agrária, Instituto Politécnico de Coimbra, Bencanta 3045-601 Coimbra \\ ${ }^{*}$ Corresponding author \\ mvazvelho@estg.ipvc.pt \\ TEL: $+351-258819700$ \\ FAX: $+351-258827636$
}

Received: 5 July 2014; Published online: 18 April 2015

Invited paper from the $3^{\text {rd }}$ International ISEKI_Food Conference - ISEKI_Food 2014 - Bridging Training and Research for Industry and the Wider Community - Food Science and Technology Excellence for a Sustainable Bioeconomy

\begin{abstract}
Agro-food companies are aware that the technical and soft skills of their employees directly influence business performance and, consequently, improving those skills will enhance the effectiveness and efficiency of their companies. This paper presents the main results of the AgriTraining project "Training requirements for the agro-food industry". Activities in pursuit of the objectives of this project involved: (1) analysis of the training needs in the agro-food industry in Portugal; (2) analysis of the training provision and the training organizations; (3) analysis of market trends; (4) definition of a training strategy; and (5) adjustment and development of training strategies for the agro-food sector. This last activity comprised the development of training curricula, suitable for the food sector as a whole and adjusted for the specific needs of some traditional industries, in order to promote the development and competitiveness of the agro-food industry in Portugal. Such training curricula aimed to promote the uptake of innovative technologies and methodologies, increase the ability of agro-food industries to invest and take risks, and enable adoption of European Community standards for production and marketing. Gaps in training supply were identified and the training provision was updated according to the needs of the agro-food companies. It was determined that companies need and demand knowledge and innovation to increase their competitive position for internationalization purposes. It was possible to define a training strategy based on market-orientation for agro-food differentiation.
\end{abstract}

Keywords: Agro-food industry; Skills; Training needs; Training provision; Training strategies 


\section{Introduction}

One possible means of leveraging the economic activity of food enterprises, in the face of economic recession, is to create conditions that promote an improvement in the technical and management skills of the professionals within the agro-food sector. Thus, an urgent intervention was outlined within the project "AgriTraining - Formação aplicada para o sector Agroindustrial" - COMPETE - SIAC - AAC $\mathrm{n}^{\mathrm{o}}$ 03/SIAC/2009 - Projeto $n^{0}$ 8310. Seven institutions, five from the national scientific system and two sectorial associations, formed the project consortium. Approximately 30 specialized people within this consortium developed the project in collaboration with several external organizations. The strategic objectives of the AgriTraining project were as follows: (1) Evaluate, define and organize a training provision oriented for the agro-food sector; (2) Develop training products, varied and flexible, suitable to the target audience; (3) Create curricula for professionalizing courses that fulfil both labour market trends and the specific needs of companies; (4) Organize training plans; and (5) Disseminate and set-up a database of training provision and professional profiles. Activities in pursuit of these objectives involved:

1 - analysis of the training needs of the agrofood industry in Portugal;

2 - analysis of the training provision and training institutions;

3 - analysis of market trends;

4 - definition of a training strategy;

5 - adjustment and development of training strategies for the agro-food industry. This paper is divided in five sections according to the stated objectives and subsequent actions.

\section{Analysis of training needs of the agro-food industry in Portugal}

\subsection{Materials and Methods}

Knowledge of the training needs of producers and companies within the agro-food sector fosters knowledge transfer and cooperation amongst companies. Four sequential methodological stages, as described by Gaspar et al. (2013b), were adopted:

Stage 1 - Determining the training needs;

Stage 2 - Defining a stratified sample of agrofood companies;

Stage 3 - Structuring the screenplay and building the online questionnaire; and

Stage 4 - Implementing interview processes and online survey.

The analysis of training characteristics and requirements set out in this section will be used to define the economic environment and identify implications for agro-food companies. This data set will then be used to design the strategy that meets the training needs identified in the companies of this business sector.

\section{Definition of Stratified Sample}

The required information to define the sample was obtained from the Gabinete de Estratégia e Planeamento of Ministério do Trabalho e da Solidariedade Social (GEP/MSSS) based on the names and numbers of enterprises and staff of the agro-food sector (MTSS, 2010). In order to validate the information provided by the GEP/MSSS a comparison was made with data from the Instituto Nacional de Estatística (INE, 2009). Both sources identified about 21,000 companies. However, from 2008, with the heightening of the economic and financial crisis and the fall in domestic consumption, the number of companies to cease trading in the agro-food sector rose steadily. Nevertheless, using the above mentioned number of potential companies, the survey sample size was determined using a $95 \%$ 
confidence level, within a $5 \%$ confidence interval. 400 companies were chosen for face-to-face interviews in order to improve the representativeness of the results and to reduce the uncertainty of answers associated with several questions that could be misunderstood by the subjects. Additionally, to widen the scope of the study, two employees from each company, at opposite ends of the hierarchical chain: top and bottom, were interviewed. Therefore, the final number of faceto-face interviews rose to 800 . Since one task of the project was to evaluate and organize the existing training provision oriented for the agrofood sector in a national scope, the survey was performed in companies located in different geographical regions, belonging to different activity sectors and having different dimensions. The stratification of companies to interview followed the criteria:

$\mathbf{1}^{\text {st }}$ Criterion: geographical distribution of companies: Portugal is divided into three Nomenclature of territorial units for statistics (NUTS I), subdivided in 7 NUTS II, and further subdivided in 30 NUTS III. Companies to be surveyed were subdivided by NUTS II according to the location of project partners (North region: 171; Central region: 107; Alentejo: 112);

$2^{\text {nd }}$ Criterion: distribution of companies by sector of activity (Classification of Portuguese economic activities by sector of activity (CAE): CAE A (Agriculture, livestock, hunting, forestry and fishing): 286 , CAE C (Manufacturing): 114);

$3^{\text {rd }}$ Criterion: companies dimension (micro, small, medium and large enterprise): The adoption of this criterion aimed to give adequate representation to enterprises of different sizes and was implemented based on the number of employees;

$4^{\text {th }}$ Criterion: geographical distribution of companies by NUTS III (Through this criterion, it was intended to give greater representation to territorial sample, so all NUTS III were covered); and $5^{\text {th }}$ Criterion: the absence of email address: Companies without email address will be part of the live inquiry.

Moreover, as the email addresses of companies in the agro-food sector were collected from the data provided by the GEP/MSSS (different companies selected for face-to-face inquiry), the project consortium also decided to perform an online survey. The online survey was sent to the general email address of the companies, after prior validation (detection and correction of errors, multiplication of identical addresses for different companies, etc...). Approximately 4,000 email invitations to the online survey were sent to other companies in the agro-food sector. After closure of the online survey, only 55 online responses were validated. Therefore, at the end of survey process, 806 (face-to-face) plus 55 (online) responses were collected.

\section{Structuring the screenplay and building the online questionnaire}

This step involved the definition of the screenplay for the face-to-face interview and online questionnaire, which required consideration of a multiplicity of issues directly related to the levels/degrees of education and training needs of employers and employees. The application used by interviewers to load the answers from employers and employees automatically built the database after the end of the face to face interview process. The same happened with the online survey of selected companies, although this was associated with another link. After loading the 800 face-to-face interview results and closure of the online survey, the data collected was exported to a spreadsheet (Excel) by the online application in CSV (Coma Separate Values) compatible format.

\section{Implementing the interview processes and online survey}

In order to quickly proceed with the face-toface interviews, an interview team was selected. It comprised four properly qualified people who were given specific training. Face-to-face interviews took place between October $15^{\text {th }}$ and 
Agro-Food Training | 15

November $27^{\text {th }}$ of 2012 , resulting in 806 validated (on either paper or online forms) completions. The Web Survey was published online on November $15^{\text {th }}, 2012$. The reliability of e-mail addresses and the unavailability of directors to answer survey questions limited the number of responses (55 validated).

\subsection{Results and Discussion}

A critical analysis of the data collected allowed the specific objectives to be met. A global overview of the human resources within agrofood industries was determined in order to assess the main strengths and weaknesses of their human resources, and to identify the key training needs for directors and their employees. The most frequently identified training needs found in this study are listed in Table 1.

\section{Analysis of the training provision and training institutions}

\subsection{Materials and Methods}

In order to detail the available training provision in Portugal, the training plans were grouped and analysed by reference level of qualification, as defined by the European Qualifications Framework (EQF):

1 - Bachelor's degree (Level VI of the Vocational Education and Training: VET system) available in higher education institutions, with interest for the agro-food sector;

2 - Postgraduate, Masters -MSc- and Doctorate -PhD- degrees (Level VII of the VET system) that may be important for the various stakeholders in the agro-food sector; and

3 - Qualification of level II (3rd cycle of basic education - lower secondary education) to level V (Post-secondary non-higher level qualification such as provided by Technological Specialization Courses -CET-) of VET system, with interest for the agro-food sector.
A survey of the training and educational institutions that provide specific training for the agrofood industrial sector was considered as an important diagnostic tool. The results of this analysis allowed training scenarios to be highlighted, both in terms of geographical dispersion of training institutions, and in terms of their qualification/expertise to teach at the various skill levels. A detailed analysis was presented by Gaspar et al. (2013a).

\subsection{Results and Discussion}

The results are divided in two groups according to the EQF levels of qualification: qualification levels V to VIII (CET to PhD qualification) and qualification levels II to IV $\left(3^{\text {rd }}\right.$ cycle of basic education - lower secondary education to Secondary education qualification)

\section{Training offer and training institutions (qualification level $\mathrm{V}$ to VIII)}

An analysis of the training provision at qualification levels V to VIII, and from the Technological Specialization Courses (CET) to the higher training levels (Bachelor, Postgraduate, Master and Doctorate) relevant to the agro-food sector is presented. Table 2 shows all educational provision directed to the agro-food industrial sector across the seven NUTS II: Northern region, Centre region, Lisbon, Alentejo, Algarve, Azores and Madeira. The training provision directed to the agro-food sector, for qualification levels V to VII, shows the following features:

1 - 57 institutions provide training of interest for the sector;

2 - The Northern Region shows the greatest number of training organizations and training courses;

3 - The CET qualification was the most frequently expressed, with a training provision of 118 and 80 matched courses;

4 - The number of Bachelor (74) and MSc (73) courses is almost the same, as determined by an analysis of authorized courses by the 
16 | Gaspar et al.

Table 1: Topics with greater representation from all areas of education

\begin{tabular}{|c|c|c|c|c|c|}
\hline \multirow[b]{2}{*}{$\mathbf{n}^{\mathbf{o}}$} & \multirow[b]{2}{*}{ Themes } & \multirow{2}{*}{$\begin{array}{l}\text { Areas of } \\
\text { formation }\end{array}$} & \multicolumn{3}{|c|}{$\%$ inquired $(n=806)$} \\
\hline & & & Total & Top & Base \\
\hline 1 & Implementing a culture of prevention in OHS & QEHS & 67.6 & 33 & 32.5 \\
\hline 2 & Planning, monitoring and controlling production & $\mathrm{OM}$ & 62.8 & 34.1 & 25.4 \\
\hline 3 & Quality control & Technical area & 62.4 & 31.9 & 28.7 \\
\hline 4 & Implementing a culture of prevention in HACCP & QEHS & 60 & 29.9 & 28.3 \\
\hline 5 & Identify, analyse and control risks & QEHS & 57.1 & 28.8 & 26.6 \\
\hline 6 & Ability to comply with objectives & PBD & 55.6 & 27.7 & 25.4 \\
\hline 7 & Motivate people & PBD & 54.6 & 28.1 & 23.7 \\
\hline 8 & Know how to handle Office tools & Informatics & 53.8 & 27.5 & 23.7 \\
\hline 9 & $\begin{array}{l}\text { Organize and manage time } \\
\text { (image management and protocol) }\end{array}$ & SAW & 53.3 & 27 & 24.1 \\
\hline 10 & Know how to manage and control stocks & Commercial & 53.1 & 27.7 & 23.7 \\
\hline 11 & Know applicable legislation & QEHS & 53 & 28.3 & 22.8 \\
\hline 12 & Lead and motivate work teams & PBD & 52.2 & 27.5 & 22 \\
\hline 13 & Initiative & PBD & 52 & 28.3 & 22.3 \\
\hline 14 & $\begin{array}{l}\text { Know how to communicate and express themselves } \\
\text { (written and oral communication) }\end{array}$ & $\mathrm{PBD}$ & 50.7 & 25.7 & 23.6 \\
\hline 15 & Know how to manage conflict situations & PBD & 50.1 & 24.9 & 23.7 \\
\hline 16 & Identify market trends & Marketing & 50 & 25.9 & 20.8 \\
\hline 17 & $\begin{array}{l}\text { Develop methods and techniques to } \\
\text { preserve the environment }\end{array}$ & QEHS & 48.6 & 24.8 & 22.3 \\
\hline 18 & English & Foreign Languages & 48.5 & 23.1 & 22 \\
\hline 19 & Apply methods for solving quality problems & $\mathrm{OM}$ & 45.7 & 23.4 & 21 \\
\hline 20 & Apply sales techniques and negotiation & Commercial & 44.8 & 23.1 & 19.9 \\
\hline 21 & Air conditioning and industrial refrigeration & Technical area & 43.7 & 22.7 & 20 \\
\hline 22 & Know how to manage stocks & AFM & 43.4 & 25.8 & 16.4 \\
\hline 23 & New technologies in the food area & Technical area & 42.8 & 20.7 & 20.3 \\
\hline 24 & Deal with difficult situations (e.g. difficult recoveries) & Commercial & 41.8 & 22.2 & 17.6 \\
\hline 25 & Know how to use HACCP software & Informatics & 38 & 19.5 & 16.7 \\
\hline 26 & Develop methods and techniques for exploration & Commercial & 37.6 & 18.9 & 16.5 \\
\hline 27 & Plan industrial maintenance & $\mathrm{OM}$ & 37.2 & 19.5 & 16.6 \\
\hline 28 & Management processes for innovation (new products) & MIK & 37.2 & 18.7 & 17.7 \\
\hline 29 & Continuous improvement (lean management, 6 -sigma) & Technical area & 36.8 & 19.5 & 16.4 \\
\hline 30 & Product life cycle analysis & QEHS & 36.5 & 19.5 & 16.5 \\
\hline 31 & Processing / optimization of processes / products & Technical area & 34.6 & 17 & 16.3 \\
\hline 32 & Know how to manage emotions & PBD & 34.5 & 18.1 & 16 \\
\hline 33 & Industrial maintenance & Technical area & 34.4 & 16.9 & 15.9 \\
\hline 34 & Skills in environmental management & QEHS & 34.1 & 18.5 & 14.9 \\
\hline 35 & Evaluate the effectiveness of an organization & $\mathrm{OM}$ & 31.1 & 15.3 & 14.9 \\
\hline 36 & $\begin{array}{l}\text { Management of product life cycles } \\
\text { (Process development) }\end{array}$ & MIK & 29.7 & 14.8 & 13.8 \\
\hline
\end{tabular}

AFM: Administration and Financial Management; HACCP: Hazard Analysis and Critical Control Points; MIK: Management of Innovation and Knowledge; OHS: Occupational Health and Safety; OM: Operational Management; PBD: Personal/Behavioural Development; QEHS: Quality, Environment, Hygiene and Safety; SAW: Secretary and Administrative Work 
Agro-Food Training |17

Directorate-General for Higher Education of Portugal;

5 - The Northern Region, Lisbon and Alentejo offer the four levels of qualification;

6 - Algarve, Azores and Madeira, do not have the variety of qualifications (no $\mathrm{PhD}$ degrees available), compared to other regions; and

7 - Madeira only has CET that meet the agrofood sector needs.

\section{Training provision and training institutions (qualification level II to IV)}

The qualification levels II to IV and Units of Short Term Training (UFCD) relevant to agrofood sector are distributed across three fields: agricultural production, animal production and complementary. The results are quantified in Table 3. Based on an analysis of the results, it can be stated that:

1 the subjects of Maintenance, Automation and Quality Control are those with the highest number of qualifications;

2 in the field of Agricultural Production, Wine and Olive Oil provision predominates;

3 in the field of Animal Production, the largest number of qualifications is presented by the Meat sector;

4 CET have a significant expression in the fields referred to above;

5 none of the CET training provision is considered relevant by the agro-food sector in the fields of Fish, Logistics, Design and Packaging; and

6 there is no CET provision on Packaging, although Packaging concepts and skills are included in courses directed for the agrofood areas of Agricultural Production, Animal Production and Complementary. There are courses in Packaging at higher qualification levels (postgraduate and Master).
When surveying the training provision available some difficulties arose which prevent a full analysis. At the start of the study, various public and private organizations were committed to give information about the available training provision in the framework of the agro-food sector for qualification levels II to IV. Much of the training provision at that level is dispersed among ministries, school clusters, professional schools and several other private companies. In Portugal, there is no single database for courses with qualification levels II to IV, and thus face-to-face contact with each of the training organisations would be needed to check their training provision. On the other hand, the information contained on web pages of the institutions and training organizations advertised the currently available training provision, and did not mention the provision that had already taken place. Furthermore, training organizations often have no previously defined curricula, because they collect fees from trainees and only after that do they define the curricula according to the preferences of subscribers. Also there are training institutions that during the same year perform more than one action in levels II to IV and USTT, such as the training curricula funded by the Operational Program for Human Resources (POPH) and the Program for rural development (PRODER) through protocols with others (associations, cooperatives). Some of these courses end up outside the geographical area of the original training institution thus hindering its quantification. In addition, the same course may be advertised by more than one organization, by the training institutions or by intermediary organisations belonging to different geographical areas. Since it was not possible to determine accurately the data of specialized training curricula funded under the PRODER program, they were excluded from the present study.

Finally, it is important to mention that the majority of the analysed CET have their own references, and when analysing the content of their curricula a wide disparity in the profile provided was found. This condition increased the difficulty of data analysis. However, this disparity in content can be considered as positive since it provides a wider training provision. 
18 | Gaspar et al.

Table 2: Training provision within the NUTS II regions of Portugal (qualification levels V to VIII)

\begin{tabular}{ccccccccc}
\hline $\begin{array}{c}\text { Qualification } \\
\text { Levels }\end{array}$ & $\begin{array}{c}\text { Northern } \\
\text { region }\end{array}$ & $\begin{array}{c}\text { Central } \\
\text { region }\end{array}$ & Lisboa & Alentejo & Algarve & Açores & Madeira & Total \\
\hline CET & 29 & 43 & 20 & 16 & 4 & 5 & 1 & 118 \\
Bachelor & 25 & 20 & 13 & 11 & 4 & 1 & 0 & 74 \\
Postgraduate & 4 & 3 & 1 & 1 & 0 & 1 & 0 & 10 \\
Master & 26 & 17 & 12 & 12 & 3 & 3 & 0 & 73 \\
Doctorate & 7 & 0 & 3 & 1 & 0 & 0 & 0 & 11 \\
Total & 91 & 83 & 49 & 41 & 11 & 10 & 1 & 286 \\
No institutions & 22 & 13 & 15 & 4 & 1 & 2 & 1 & 58 \\
\hline
\end{tabular}

Table 3: Number of qualifications available in agro-food areas (qualification levels II to VI)

\begin{tabular}{llcccc}
\hline Areas & & \multicolumn{3}{c}{ Qualifications } & \multirow{2}{*}{ Total } \\
\hline General & Specific & II & IV & V & \\
\cline { 1 - 4 } Agricultural Production & Horticultural & 1 & 1 & 4 & 6 \\
& Fruit & 1 & 1 & 4 & 6 \\
& Cereals & 2 & 1 & 2 & 5 \\
& Olive Oil & 1 & 1 & 5 & 7 \\
& Wine and Vine & 1 & 1 & 7 & 9 \\
Animal Production & Dairy & 1 & 1 & 3 & 5 \\
& Meat & 2 & 1 & 4 & 7 \\
& Fish & 2 & 2 & 0 & 4 \\
& Cold chain & 1 & 3 & 3 & 7 \\
& Packaging* & 0 & 0 & 0 & 0 \\
& Logistics & 2 & 3 & 0 & 5 \\
Complementary & Quality Control & 0 & 4 & 8 & 12 \\
& Marketing & 0 & 2 & 2 & 4 \\
Others & Design & 0 & 3 & 0 & 3 \\
\cline { 1 - 3 } & Automation & 0 & 3 & 8 & 11 \\
& Maintenance & 1 & 3 & 11 & 15 \\
& Others & 0 & 0 & 2 & 2 \\
\hline
\end{tabular}

* Packaging concepts and skills are included in courses directed for the agro-food areas of Agricultural Production, Animal Production and Complementary 


\section{Analysis of market trends}

\subsection{Materials and Methods}

The analysis of market trends to guide the implementation of future training provision covered turnover and differentiating factors, and its potential compared to international trends (AgriTraining, 2011). An online survey was conducted in 206 agro-food companies. An online platform was developed specifically for this purpose.

\subsection{Results and Discussion}

The sectors found to be more important and decisive in terms of leveraging the Portuguese agrofood sector were:

- In terms of turnover:

- Processing and preservation of meat and meat products;

- Baking production;

- Processing of dairy products; and

- Other food products.

- In terms of differentiating factors compared to international trends and potential:

- Wine production;

- Tea and coffee processing;

- Sugar processing; and

- Processing and preservation of fish, crustaceans and molluscs.

The companies in the Portuguese agro-food sector, independent of the subsector to which they belong, consider that competitiveness may be accomplished by looking for new markets and business areas, recognizing and capitalizing on their brand in the international market, and increasing the efficiencies of the organization and its business processes. In order to achieve these objectives, agro-food companies considered that the training areas more relevant for their future would be:

- New technologies and processes;

- Management;
- Quality;

- Environment;

- Sustainability;

- Machinery and equipment;

- Electronics; and

- Informatics.

The skills that are most relevant to each of the above mentioned training areas are shown in Table 4 .

\section{$5 \quad$ Training Strategy}

\subsection{Materials and Methods}

The training strategy was designed to meet the previously identified needs of the surveyed companies within the agro-food sector, according to Paiva et al. (2013) methodology, thus contributing to the improvement of their operating performances and enabling the sector to embed essential skills for the development and improvement of competitiveness. The development of a national training strategy is based on methodologies for a business strategy. Thus, the intention is to reach objectivity and impact, within a national framework of provision without duplication of training plans, but specifically geared to the specific needs of the agro-food sector. With this goal in mind, a training strategy to categorize and reflect the results of diagnoses was outlined:

1 Define the strategic plan of training;

2 Identify the subsectors where filling a training gap is a priority;

3 Identify the training curricula that needs to be adjusted or created;

4 Articulate the training needs, trends and provision; and

5 Communicate with the training organizations and organizations involved. 
Table 4: The competences which are most relevant to the identified training areas

\begin{tabular}{|c|c|}
\hline Training areas & 5 Central competences most relevant to each area \\
\hline New technologies and processes & $\begin{array}{l}\text { (1) Application of models to maximize economic benefits; } \\
\text { (2) Management of the production chain; } \\
\text { (3) Ability to work with technology securely and according to standards of work; } \\
\text { (4) Competitive leadership team production; } \\
\text { (5) Work with others in a team. }\end{array}$ \\
\hline Management & $\begin{array}{l}\text { (1) Ability to coordinate; } \\
\text { (2) Decision on financial resources; } \\
\text { (3) Ability to organize; } \\
\text { (4) Entrepreneurial thinking; } \\
\text { (5) Management of human resources }\end{array}$ \\
\hline Quality & $\begin{array}{l}\text { (1) Knowledge of programs for total quality management and continuous } \\
\text { improvement; } \\
\text { (2) Implementation of systems for quality management; } \\
\text { (3) Ability to develop plans for continuous improvement of the organization; } \\
\text { (4) Planning a system of quality management; } \\
\text { (5) Knowledge of standards for certification of the company and the ability } \\
\text { to develop plans to improve the production process. }\end{array}$ \\
\hline Environment & $\begin{array}{l}\text { (1) Knowledge of environmental legislation applicable to the company; } \\
\text { (2) Creation of industrial recycling plans; } \\
\text { (3) Knowledge on environmental licensing; } \\
\text { (4) Knowledge of programs for environmental management; } \\
\text { (5) Planning environmental licensing. }\end{array}$ \\
\hline Sustainability & $\begin{array}{l}\text { (1) Efficient and effective management of resources; } \\
\text { (2) Application of new technologies and processes; } \\
\text { (3) Developing a workplace policy and procedures for sustainability; } \\
\text { (4) Waste management (including minimization, reuse,...); } \\
\text { (5) Implementation and monitoring of environmentally sustainable work } \\
\text { practices; Updated knowledge on sustainability requirements, } \\
\text { and conservation and management of existing resources. }\end{array}$ \\
\hline Machines and equipment & $\begin{array}{l}\text { (1) Knowledge of planning and production management; } \\
\text { (2) Organization, planning and quality control machinery and equipment; } \\
\text { (3) Development of management plans of production; } \\
\text { (4) Plan and coordinate layout of machinery and equipment in an } \\
\text { industrial context; } \\
\text { (5) Knowledge of operating principles of machine elements. }\end{array}$ \\
\hline Electronics & $\begin{array}{l}\text { (1) Maintenance of electronic circuits; } \\
\text { (2) Operation of industrial electronic equipment and systems; } \\
\text { (3) Solving problems of electronic equipment; } \\
\text { (4) General knowledge of electrical engineering; } \\
\text { (5) Set-up spaces for installation of electronic equipment. }\end{array}$ \\
\hline Informatics & $\begin{array}{l}\text { (1) Knowledge of internet applications for creating Web tools; } \\
\text { (2) Knowledge of data protection and data security systems; } \\
\text { (3) Ability to learn new software applications; } \\
\text { (4) Excel; } \\
\text { (5) Knowledge of specific software applications. }\end{array}$ \\
\hline
\end{tabular}


Agro-Food Training | 21

Based on the strategy and competitiveness concepts defined by Porter (1986a), Porter (1986b), Freire (1997) and Ohmae (1982), the competitive differentiation factor chosen was: Maximizing the benefits for the consumer - seeking to identify emerging needs of consumers and developing innovative products for their satisfaction. Therefore the methodology adopted is market driven, strategically based on consumer research, competitive analysis and other environmental strengths, combined with other strategic factors (capital, research and development and human resources), and oriented towards winning a competitive advantage. Direct comparisons between the capability of the company to fit consumers' needs and expectations, and the performance of competitors are made. A balanced answer that assures the company position is sought by investing directly in the identified differentiation factors of the target segment.

\subsection{Results and Discussion}

The analysis of the characteristics and requirements set out in Section 2 was used to define the economic environment and identify the implications for the companies within the agro-food sector. Some conclusions can be drawn about how companies organize themselves, how they invest in the training of employees and the type of education provided. The main conclusions were:

- Reduction in the number of companies in this activity sector due to the economic and financial crisis;

- Indifference to issues associated with training due to the companies size (especially micro and small enterprises), business type (mostly familiar) and low qualifications and age of employers/employees;

- $74 \%$ of companies don't have a human resources department responsible for training;

- $77 \%$ of interviewed personnel participated in training actions, independent of their hierarchical position;
- $59 \%$ of companies don't have a training plan;

- The training needs of companies are high;

- $92 \%$ of companies evidence their training availability through promotion of training;

- Most training activities (adjusted/related with the tasks) took place in the company;

- Most of the training actions developed in companies are related to Occupational Health and Safety, Food Hygiene and Safety, Environment, and also Personal Skills Development;

- In the areas prioritized by the interviewees, in addition to those that have been developed in recent years and for which the market gives a satisfactory answer, emerged new areas such as operational management, technical areas and innovation and knowledge management;

- Training activities should be carried out in 1st year's quarter (lower impact on companies operation);

- Training activities should be carried out after work $(29 \%)$ or in a mixed option (working period and after work);

- Training activities should be carried out twice a week;

- Training activities should last between 20 and 60 hours (51\% of respondents);

- Training activities should take place in both the classroom and workplace; and

- Training outcomes are improved performance and improved quality of service.

According to the next step of the strategy, other training organizations were considered as competitors. Thus, based on the analysis provided in section 3, all Portuguese educational institutions offering courses with different qualification levels were considered in order to identify its characteristics. The main findings are set out in Section 3.

Table 5 shows the most relevant data that identifies: (1) the opportunities and threats arising 
from the transactional context of the agro-food sector from a training perspective; and (2) the strengths and weaknesses arising from the characteristics of the partnership that makes up this project and how it will influence the characteristics of the possible training provision and its adaptation to the actual needs of enterprises. A set of the relevant training needs of food companies, for which the supply is very limited, was identified, thus emerging as a priority to set training plans in these areas (including the definition of the training strategy and the development and adjustment of training plans). These are as follows:

Operational Management: planning, monitoring and controlling production;

Technical Areas: Air conditioning and industrial refrigeration;

Technical Areas: New technologies in the food sector;

Technical Areas: Continuous improvement (lean management, 6-sigma);

Management of Innovation and Knowledge: Management processes for innovation (new product development); and

Management of Innovation and Knowledge: Management of product life cycles.

The training provided will be transversal to the whole agro-food sector, although special consideration must be given to sectors as identified by their turnover and their potential for internationalization and differentiation. The strategic positioning of the training provision is based on vectors that arise from the competitive advantages identified: (1) Customization of training; and (2) Relocation of training.

\section{Adjustment and development of training plans}

\subsection{Materials and Methods}

Before adjusting and developing the training plans directed to the agro-food sector, an analysis of the international features of the food and beverages industry was performed. It is the largest European industrial sector and mostly composed of small and medium enterprises (SMEs) and microenterprises. The results of the European project TRACK_FAST (Training Requirements And Careers for Knowledgebased Food Science and Technology in Europe), which assessed and classified the current state of skills of professionals working in the agrofood sector, were analysed (Track_Fast, 2010). This identified that the education, training and skills of professionals in the food sector may not be following the evolution of the requirements for executing tasks required in different employment sectors (e.g. industry, research, academia government organizations). Innovation depends on skilled professionals and the skills required are not static. The key scientific and technical skills as well as general and personals skills were graded according to their importance after collecting 237 validated questionnaires, namely:

- "The ability to think and solve problems" and "being responsible" were identified as the most important skills, with respectively $64 \%$ and $59 \%$ of respondents considering it very important for their work in the future; and

- "Management of food safety, food hygiene and food safety control" was ranked as the third most important competence $(50 \%)$.

Although it may not be included in the curricula of the training provision for formative institutions, strengthening personal skills should be one of the requirements of educational programmes such as a project or internship.

\subsection{Results and Discussion}

Thus, from the integration and analysis of training needs, trends and training provision, as well as accredited training organizations identified within this study, the strategic areas of training were defined, as follows:

- New UFCD (level II) arranged into a coherent whole that allows the creation of a new 
Agro-Food Training | 23

Table 5: SWOT Analysis

\begin{tabular}{|c|c|}
\hline Strengths & $\begin{array}{l}\text { The adequacy of skills to offer training; } \\
\text { Credibility; } \\
\text { The geographical location coincident with the geographic business sector intensity; } \\
\text { Knowledge of the needs of the sector; } \\
\text { Direct access to the business sector through the partnership composition. }\end{array}$ \\
\hline Weaknesses & $\begin{array}{l}\text { The high number of competitors; } \\
\text { Does not cover the national territory. }\end{array}$ \\
\hline Threats & $\begin{array}{l}\text { Almost } 2 / 3 \text { of the companies surveyed have less than } 10 \text { employees, so most } \\
\text { a service or internal team responsible for training; } \\
\text { The relative importance of the qualifications below the } 3 \text { rd cycle in lower level } \\
\text { employees (showing no compulsory schooling around } 1 / 3 \text { and only } 8 \% \\
\text { have a degree); } \\
\text { Most of the employees did not attend other training activities promoted } \\
\text { by other organizations (besides the company); } \\
\text { The absence of a training plan in most companies; } \\
\text { Most of the companies do not have funds earmarked for training in their } \\
\text { respective annual budgets; } \\
\text { Given that the market already has enough training offered in some areas } \\
\text { and there is a set of "new" training needs in the companies for which } \\
\text { the supply is very limited, it is important to focus attention on the } \\
\text { development of training plans for these areas: Operational Management: } \\
\text { planning, monitoring and controlling the production; Technical Areas: Air } \\
\text { conditioning and industrial refrigeration; Technical Areas: New technologies in } \\
\text { the food area; Technical Areas: Continuous improvement (lean management, } \\
6 \text {-sigma); Management of Innovation and Knowledge: Management } \\
\text { processes for innovation (new product development); Management } \\
\text { of Innovation and Knowledge: Management of product life cycles; } \\
\text { The training entities should develop and submit training plans geared to the actual } \\
\text { needs of enterprises/employees, performing the actions proposed in the premises } \\
\text { of the companies (in class and in work context). }\end{array}$ \\
\hline Opportunities & $\begin{array}{l}\text { Most of the employees of "top", including associate directors, has high } \\
\text { school and/or a degree and is sensitive to the need for increased training; } \\
\text { The Training Experience of employees and enterprises is recognized } \\
\text { as important for productivity and competitiveness; } \\
\text { Important for the training organizations to increase promotion of provision } \\
\text { and for a policy of greater pro-activity among potential trainees, highlighting } \\
\text { the huge benefits for their business to develop training plans targeted to their } \\
\text { actual needs (due to a greater understanding of the profile and weaknesses } \\
\text { that characterize the human resources); } \\
\text { Guide and adapt the curricula plans to characteristics valued by the } \\
\text { interview participants (to be held in the } 1 \text { st quarter, after work hours, twice } \\
\text { a week, with a duration between } 20 \text { and } 60 \text { hours in the classroom } \\
\text { and in the workplace). }\end{array}$ \\
\hline
\end{tabular}

IJFS | April 2015 | Volume 4 | pages 12-28 
24 | Gaspar et al.

course directed to the dairy sector: "Operator of Preparation and Processing of Dairy Products";

- CET in the area of "Agro-industrial Production Control" (level V), since it is intended to inform professionals dealing with operational planning, monitoring and control of production in agricultural storage facilities;

- MSc in "Continuous Improvement and Innovation in Agro-industrial Sector" (level VII) that aims to provide the skills necessary for application of processes, procedures, methods and tools aimed for improving the processes associated with the agro-food sector;

- MSc in "Agro-industrial Planning and Maintenance" (level VII) which will include subjects related to project, installation and maintenance of air conditioning and industrial refrigeration systems used in the agrofood sector; and

- MSc in "Agro-industrial Management" (level VII) which will include topics related to life cycle analysis, continuous improvement and innovation management in the agro-food sector.

\section{Specialized courses level II}

The dairy industry has a relatively high weight in the Portuguese agro-food sector, but there is no specific training, at any level, exclusively geared for this subsector. Since the level of innovation and production control is significantly lower in these predominantly small/medium enterprises, it was considered advantageous to propose a set of UFCD that, taken together, organize themselves into a coherent whole that allows to propose a specialized course level II "Technical Operator of Milk and Dairy Products". Thus, in AgriTraining (2013) a proposal of 15 a UFCD to make up the technological framework of a course of this nature was presented. The descriptors of the courses listed in the curriculum were also proposed. The descriptors include the major issues that should be addressed but are not intended to be a limiting approach in terms of content.

\section{Technological Specialization Course (CET)}

The findings from the analysis of the results of the activities set forth in the preceding sections, proved the need of a curricular profile of 60 ECTS (European Credit Transfer System) of a technological specialization course in Agro-industrial Production Control as shown in Table 6. General skills were defined with an equivalent weight, and preference was given for technological skills directly related to production, such as facilities, equipment and food technologies. It is recommended that the curricular profile, together with the internship project (corresponding to 20 ECTS) making a total of 80 ECTS, seeks to properly develop a set of personal skills that will be crucial in the future (e.g. responsibility, communication skills, adaptability to change and ability to self-learning).

\section{Masters Courses (2nd Cycle)}

Given the volume and diversity of degree courses in the food area, the Bachelor level (B.Sc.) with 180 ECTS were not considered in this study. It is suggested to adapt the training provision to the real needs of regional business, as well as increasing the interaction between training organizations and companies. However, taking into account the skills most relevant to operational management, technical areas and management of innovation and knowledge, three Master course proposals are presented. Although there are some overlapping subjects, the curricula have notably different training profiles at the level of skills in the areas of planning and maintenance, management and innovation and continuous improvement. The structure of each course is shown in Table 7. The analysis of this table allows an evaluation of the weight of ECTS credits in terms of the common component and the components more targeted to specific areas that shape the output profile of the professionals.

The proposals are not to be compulsory. The proposals are presented only as indicators in order to allow an institution, wishing to provide this information, to adapt them to the internal reality and to the needs of companies for which it is intended to prepare professionals. On the 
Agro-Food Training | 25

Table 6: The curriculum of the specialization technology course (CET) in Agro-industrial Production Control

\begin{tabular}{|c|c|c|c|c|c|}
\hline \multicolumn{6}{|c|}{ General and Scientific Training } \\
\hline Area & Formation Unities & Tot. Hour & $\mathrm{C}$ & $\mathbf{P}$ & ECTS \\
\hline 482 & Informatics Applications & 38 & 25 & 20 & 1.5 \\
\hline 862 & Safety, Hygiene and Health at Work & 38 & 25 & 20 & 1.5 \\
\hline 321 & Technical Information and Communication & 38 & 25 & 20 & 1.5 \\
\hline 347 & Business Organization & 38 & 25 & 20 & 1.5 \\
\hline 541 & General Chemistry & 38 & 25 & 20 & 1.5 \\
\hline 541 & General Microbiology & 38 & 25 & 20 & 1.5 \\
\hline & TOTAL & 228 & 150 & 120 & 9 \\
\hline \multicolumn{6}{|c|}{ Technology Training } \\
\hline Area & Formation Unities & Tot. Hour & $\mathbf{C}$ & $\mathbf{P}$ & ECTS \\
\hline 541 & Food Chemistry & 38 & 25 & 20 & 1.5 \\
\hline 541 & Food Microbiology & 75 & 50 & 38 & 3 \\
\hline 541 & Agro-industrial Plant and Equipment & 75 & 50 & 38 & 3 \\
\hline 541 & Instrumentation, Automation and Control & 75 & 50 & 38 & 3 \\
\hline 541 & Agro-industrial Equipment Maintenance I & 75 & 50 & 38 & 3 \\
\hline 541 & Agro-industrial Equipment Maintenance II & 75 & 50 & 38 & 3 \\
\hline 347 & Industrial Planning & 75 & 50 & 38 & 3 \\
\hline 541 & Hygiene of Agro-industrial Plant and Equipment & 38 & 25 & 20 & 1.5 \\
\hline 541 & General Food Processing & 38 & 25 & 20 & 1.5 \\
\hline & Workshops Technology-Food Processing & & & & \\
\hline 541 & - Meat and Fish & 75 & 50 & 38 & 3 \\
\hline 541 & - B22Dairy products & 75 & 50 & 38 & 3 \\
\hline 541 & - Fruits and Vegetables & 75 & 50 & 38 & 3 \\
\hline 541 & - Oenology & 75 & 50 & 38 & 3 \\
\hline 541 & Food Quality Control & 75 & 50 & 38 & 3 \\
\hline 541 & Food Safety & 75 & 50 & 38 & 3 \\
\hline 541 & Storage, Logistics and Food Distribution & 75 & 50 & 38 & 3 \\
\hline \multirow[t]{2}{*}{541} & Waste Water Management and Waste water & & & & \\
\hline & in Food Industry & 38 & 25 & 20 & 1.5 \\
\hline 541 & Project I & 75 & 50 & 38 & 3 \\
\hline \multirow{2}{*}{541} & Project II & 75 & 50 & 38 & 3 \\
\hline & TOTAL & 1277 & 850 & 650 & 51 \\
\hline \multicolumn{6}{|c|}{ Work context } \\
\hline & Internship & 540 & 540 & 540 & 20 \\
\hline & TOTAL & 2045 & 1540 & 1310 & 80 \\
\hline
\end{tabular}

Legend:

Tot. Hour: Total number of hours (contact + work load)

C: Number of contact hours

P: Number of practise hours

ECTS: European Credit Transfer and Accumulation System 
26 | Gaspar et al.

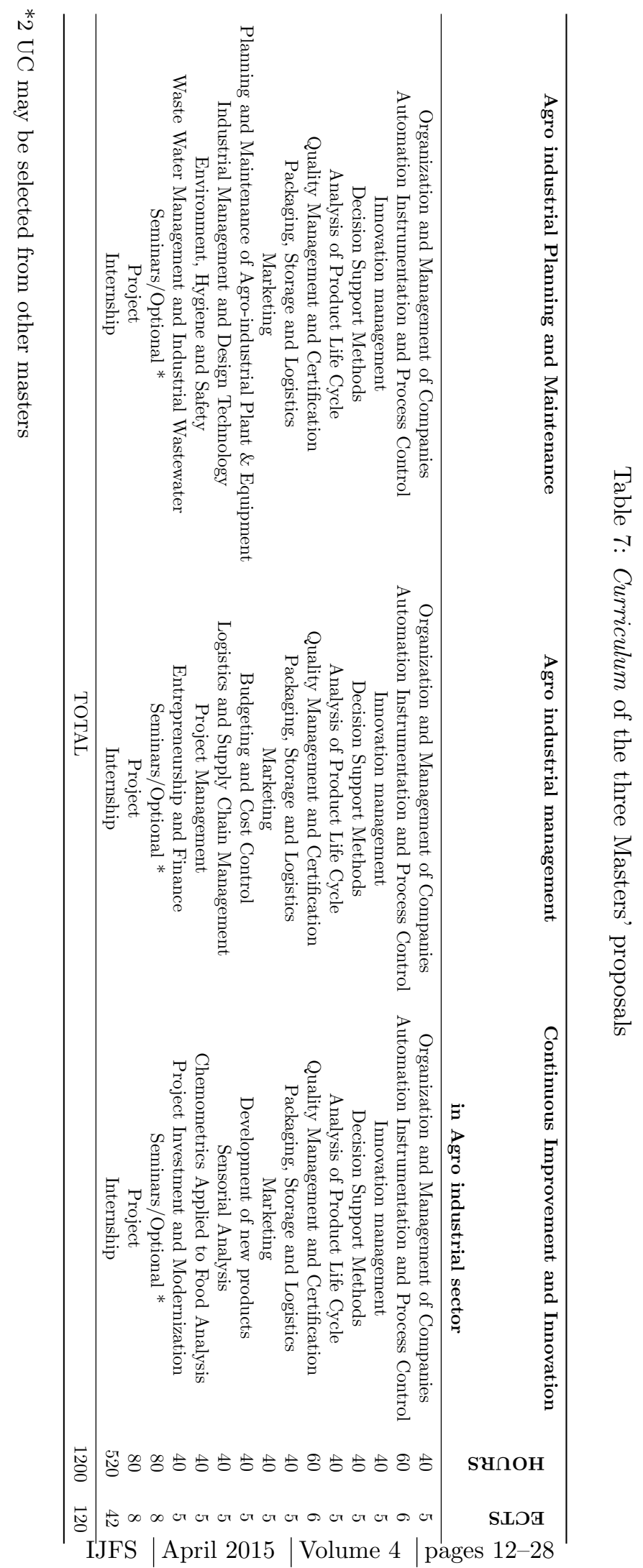


Agro-Food Training $\mid 27$

other hand, it is advised that the students on one of the masters can choose curricular units in other existing masters. Special attention must be paid to the impact that biotechnology and nanotechnology will have in the future on the agro-food sector's enterprises. The importance of developing personal skills, including the ability to communicate, to work in groups, selflearning, and innovation and foresee the evolution of the sector, is also highlighted. Thus, it is recommended that the chosen learning, teaching and assessment methods for the subjects (project, group work, oral presentation...) foster these skills. Additionally, seminars in the subject should establish a dynamic way of gathering the experience of professionals who already have developed a relevant activity in these areas. Finally, taking into account the evolutionary dynamics of society in general and industry in particular, it is recommended that the curricular profile is not viewed as a static reference but it is a versatile tool in order to monitor the changing trends of the sector.

\section{Conclusions}

From the information collected and systematized in the present study, a conclusion is drawn that, in general, Food Industry employees showed a lack of knowledge about the Portuguese educational system and referential, including the available provision at educational institutions and training organizations of their region. Food industry employees when interviewed about their training needs highlighted several areas that were already, partially or totally, covered by a significant variety of courses and Units of Short Term Training (UFCD) from the different qualification levels. Therefore, one of the objectives of this project - to disseminate the results of the different activities in order to disclose, clarify and assist companies in the agro-food sector to improve the skills of its employees, was achieved. After a thorough analysis of the agro-food sector, under a competitive market perspective, it was possible to identify gaps in the training provision and the actual needs of companies. It was found that food companies still need training and knowledge transfer, and are aware of the need to increase their competitiveness, so that they can be international and sustainable. Furthermore, training is recognised as an important tool to achieve that. When comparing the qualification training in European terms, Portugal still has a long way to go and Portuguese food companies still need training suited to the hierarchy positions of their employees. With this project, it was possible to define a training strategy for agro-food companies based on product differentiation and market-orientation. The proposed training courses are important tools for improving the competitiveness of the agro-food sector by strengthening the general and scientific expertise of its employees. Besides fostering the technical and scientific skills of employees that will contribute to the company's competitiveness, training will also be a landmark for the job and career of the employee. The implementation of these proposals will depend on the specific training strategy of training and educational institutions, and how dissemination amongst the agro-food companies is performed.

\section{Acknowledgements}

This study is framed in activities of the anchorproject "AgriTraining - Formação Aplicada para o Sector Agroindustrial", in Eixo Estratégico II - Plataformas para a Inovação e Intermediação e Transferência do Programa de Acção da associação INOVCLUSTER: Associação do Cluster Agro-Industrial do Centro.

The study was funded by Quadro de Referência Estratégico Nacional (QREN 20072013) - COMPETE/POFC (Programa Operacional Factores de Competitividade), SIAC: 03/SIAC/2009, Ref.: 8310).

\section{References}

AgriTraining. (2011). Estudo de levantamento de tendências de mercado e competências para o futuro do sector agroindustrial. Ed. Competinov, Braga, Portugal.

AgriTraining. (2013). Ajustamento e desenvolvimento de planos formativos dirigidos ao sector agroindustrial. QREN nr 8310 
FCOMP-05-0128-Feder-008310, 2011-2013.

Ed. AgriTraining, Covilhã, Portugal.

Freire, A. (1997). Estratégia -sucesso em portugal (P. Verbo Lisboa, Ed.).

Gaspar, P., Felizardo, V., Domingues, C., Almeida, C., Paiva, T., Pereira, C. D., \& Pinheiro, R. (2013a, May). Levantamento da oferta formativa e das entidades formadoras para o sector agro-industrial em portugal. In International Congress on Safety and Labour Market (ICSLM 2013). Covilhã, Portugal.

Gaspar, P., Felizardo, V., Domingues, C., Almeida, C., Paiva, T., Pereira, C. D., \& Pinheiro, R. (2013b, May). Levantamento das necessidades formativas no sector agroindustrial. In International Congress on Safety and Labour Market (ICSLM 2013). Covilhã, Portugal.

INE. (2009). Anuário Estatístico de Portugal. Instituto Nacional de Estatística.

MTSS. (2010). Quadro de pessoal. Ministério do Trabalho e da Solidariedade Social.

Ohmae, K. (1982). The mind of the strategist: the art of japanese business. McGraw-Hill Professional.

Paiva, T., Gaspar, P., Felizardo, V., Domingues, C., Almeida, C., Pereira, C., \& Pinheiro, R. (2013, May). Estratégia formativa para o sector agro-industrial. In International Congress on Safety and Labour Market (ICSLM 2013). Covilhã, Portugal.

Porter, M. (1986a). Estratégia competitiva: técnicas para a análise de indústrias e da concorrência. 7 Ed., Ed. Campus Lda. Rio de Janeiro, Brasil.

Porter, M. (1986b). Vantagem competitiva: criando e sustentando um desempenho superior. 6 Ed., Ed. Campus Lda. Rio de Janeiro, Brasil.

Track_Fast. (2010). Report on deliverable D1.1: The current State of European FST Competencies. TRACK_FAST - Training Requirements And Careers for Knowledgebased Food Science and Technology in Europe (Project nr. 227220, FP7-2009-2013). 